\title{
State of research and future research tendencies in lean healthcare: a bibliometric analysis
}

\author{
Lukas D. Filser ${ }^{1}$ - Fábio Francisco da Silva ${ }^{2}$ Otávio José de Oliveira ${ }^{2}$
}

Received: 27 August 2016/Published online: 23 May 2017

(c) Akadémiai Kiadó, Budapest, Hungary 2017

\begin{abstract}
The application of Lean Philosophy in a healthcare environment is still a relatively new field of research, but there already exists a considerable amount of literature on the topic. This article structures, analyzes and interprets the data of articles on Lean Healthcare from 2002 through 2015 bibliometrically. The databases used in order to realize the analysis are the main sources for citation data available: Elsevier's Scopus and Thomson Reuters' Web of Science. The scientific contribution of this article lies in structuring the literature on Lean Healthcare and summarizing future research proposals. Thereby it encourages the review and consolidation of existing directions in this field of research and the exploration of new ones. With respect to the article's applied contribution it helps hospitals and professionals which want to apply Lean Healthcare to deal with uncertainties and challenges before or during its implementation by granting easy access to the literature. It also allows adapting suitable findings of major publications for the practical implementation with the goal to improve the patient experience. As results of this bibliometric analysis it was found that J.E. Bassham and D.I. Ben-Tovim share the first place as most cited authors in Lean Healthcare and the Linköpings Universitet is the most cited institution. With respect to countries, the United States take the first rank. The most cited article is Trends and approaches in lean healthcare by L. Brandão de Souza which was published in the most cited journal, namely Leadership in Health Services. Four main tendencies for future research possibilities in Lean Healthcare were identified: Evaluate the implementation; Amplify basic knowledge; Investigate challenges and success stories; Expand the focus.
\end{abstract}

Keywords Lean Healthcare - State of research · Future research · Scientific impact $\cdot$ Bibliometric analysis

Otávio José de Oliveira

otaviodeoliveira@uol.com

Universität Duisburg-Essen, Forsthausweg 2, 47057 Duisburg, Germany

2 Sao Paulo State University - UNESP, Av. Doutor Ariberto Pereira da Cunha, 333 -Campus

Guaratinguetá, Guaratinguetá, SP 12516-410, Brazil 


\section{Introduction}

"Good Health and Well-Being" is one of the major priorities in our society which manifests itself as one of the 17 Sustainable Development Goals of the United Nations (United Nations 2015). Therefore, there should be an omnipresent pursuit of improving health and well-being. Companies continuously need to improve in order to stay competitive (Gonzalez and Martins 2015) and thus, it makes sense to transfer industrial improvement approaches to healthcare in order to improve health and well-being (Printezis and Gopalakrishnan 2007; Spear 2005). One of those improvement approaches is Lean Philosophy which transfers to Lean Healthcare (Brandão de Souza 2009). As Lean Healthcare is a relatively new topic with rising importance, its profound investigation in literature is paramount. Bibliometric analyses support in this as they offer information that is "highly compact, easy to handle, and likely to be objective" (Diem and Wolter 2013) and therefore help to comprehend how the field of research is structured. By doing so, they support decision-making, point out significant and promising research areas, recognize trends (Ball 2006) and make these trends understandable (Thomson Reuters 2008).

Lean Philosophy describes a set of principles and methods in industrial production to improve profit margins, market share and product quality by continuously improving processes and respecting people in terms of customer satisfaction and well-being of employees (Kim et al. 2006; Liker 2004). Healthcare comprises the efforts of health professionals with the ultimate goal of maintaining and improving health and one of the key elements to achieve this goal is to organize health services around the needs and expectations of people (Merriam-Webster 2015; World Health Organization 2016).

As the name implies, Lean Healthcare is about applying Lean Philosophy in a healthcare environment. In its core, it is about understanding what is valuable to the patient and distinguishes between activities that add value by directly contributing to what the patient desires and those that do not. Activities that do not add value are called waste and ought to be avoided or removed (Fillingham 2007; Joosten et al. 2009).

So as to tackle "challenges of safety, quality, efficiency, and appropriateness in order to improve system reliability and timeliness" (Kim et al. 2006) in healthcare, it makes sense to transfer the Lean Philosophy to this area. While increasing the value which is received by the customer refers to the manufactured product in manufacturing, in a healthcare environment it mainly transfers to the patient experience. This means parting from the common approach to focus only on the clinicians in terms of maximizing efficiency and minimizing waste and concentrate more on the patients instead (Dickson et al. 2009).

Brandão de Souza (2009), Fillingham (2007), Joosten et al. (2009), Kim et al. (2006) and Kollberg et al. (2007) agree that healthcare benefits from the introduction of Lean Philosophy. Brandão de Souza (2009) states that two aspects intrinsic to Lean, namely "staff empowerment and the concept of gradual and continuous improvement" make it more applicable for healthcare than other improvement approaches. Sustainable results and positive evidence with respect to staff and customer satisfaction, cost, time and quality aid in establishing acceptance towards Lean Healthcare (Brandão de Souza 2009; Papadopoulos et al. 2011; Radnor et al. 2012).

The importance of Lean Healthcare in literature rose significantly in the last 10 years with a tendency to rise even further in the years to come, as can be seen in Fig. 1 which shows the evolution of the accumulated number of publications on Lean Healthcare according to the search conducted for this article (see "Research methodology" section). Despite two publications by Kästli Meier (1994) and Pfaff (1994) as early as 1994, a constant growth cannot 


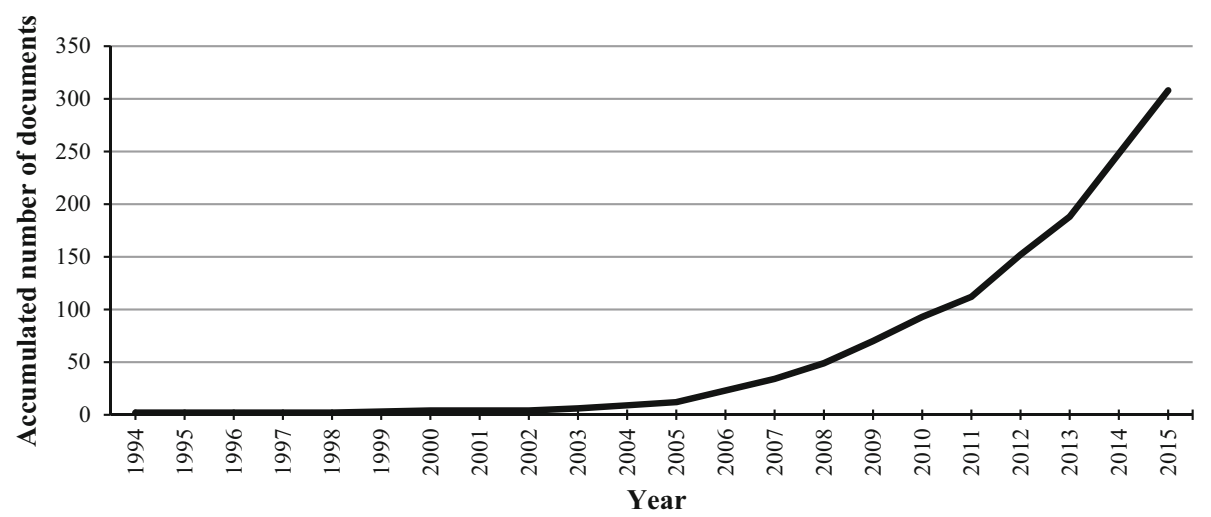

Fig. 1 Accumulated number of documents on Lean Healthcare (Based on the Scopus and WOS data resulting from the search as described in "Research methodology" section)

be seen until after the year 2002 which is in concordance with the observation of Brandão de Souza (2009) that Lean Healthcare was first applied around 2002.

As previous studies on Lean Healthcare are often based on specific and narrow research questions and require updates in some cases (D'Andreamatteo et al. 2015), there is opportunity to realize a comprehensive and up-to-date bibliometric analysis on Lean Healthcare as performed in this article.

While other recent literature reviews (Costa and Godinho Filho 2016; D'Andreamatteo et al. 2015; Moraros et al. 2016) on the topic exist, they concentrate on analyzing the qualitative content of the literature on Lean Healthcare. As opposed to this article they do not analyze bibliometric data quantitatively except for analyzing different countries on their share of publications (Costa and Godinho Filho 2016; D'Andreamatteo et al. 2015). Furthermore, they include documents in which Lean is combined with other improvement methods, as in publications about Lean Six Sigma in healthcare while this article only analyzes articles which are exclusively related to Lean Philosophy in a healthcare environment.

The objective of this article is to map the state of research on Lean Healthcare in order to provide a better understanding of the structure of this field of research and the major actors in it as well as to acknowledge and support the course of existing literature. Furthermore, it analyzes future research tendencies in Lean Healthcare to inspire further work in this area.

After this introduction, second section explains the research methodology which was followed in order to achieve this goal. Thereafter, the bibliometric analysis of scientific publications on Lean Healthcare from 2002 through 2015 itself is described in third section and future research tendencies in Lean Healthcare are presented in forth section. Finally, fifth section draws a conclusion which is followed by an overview over the references which were used in this article.

\section{Research methodology}

This article carries out a bibliometric analysis on Lean Healthcare for publications of the years 2002 through 2015. A bibliometric analysis examines data of publications bibliometrically to indicate and evaluate the scientific output of different entities (OECD 2002). They are a valuable asset as they offer objective information in a concise and 
understandable form, however vast the analyzed field of research is (Diem and Wolter 2013). Thereby, bibliometric analyses represent a well-established method in order to analyze and measure the publications in a scientific area of interest (Garousi 2015).

The data for this bibliometric analysis was collected by using the two databases which are the main sources for citation data and are therefore commonly used in bibliometric analyses: Elsevier's Scopus and Thomson Reuters' Web of Science (WoS) (Mongeon and Paul-Hus 2016). Besides Scopus being the largest bibliometric database and WoS offering the most complete coverage of scientific journals, they contain the required metadata for the bibliometric analysis as described in "Bibliometric analysis" section and allow for the extraction of this metadata (Gonçalves and Perra 2015; Iritani et al. 2015). By using two different databases it was intended to lower the risk of missing documents due to different publication coverage and search algorithms. Due to the different search engines in the two databases, however, it was not possible to use the same search parameters for both.

To analyze the data of these documents bibliometrically, their corresponding metadata was imported into Microsoft Excel 2010. Both Scopus and WoS allow for downloading the results as. text-files. In the case of Scopus the file was directly imported and in the case of WoS it was processed beforehand by using Thomson Reuters' software EndNote X7. By excluding duplicates, both searches were unified in order to review the results along different criteria.

The two most common bibliometric indicators to evaluate research performance are the number of publications and the citation count. The first one is an indicator for the research output per se while the second one reflects the response that a publication receives in the academic community (Diem and Wolter 2013). The citation count reveals, how far a cited paper is useful to other publications (Zhang and Guan 2017) and to what extent it influences a given field of research. Therefore, in order to perform an analysis of the countries, institutions, journals, authors and publications with the highest research performance in "Country analysis" through "Publication analysis" section, they were ranked by their respective citation count.

Due to the fact that the same articles have different citation counts in Scopus and WoS, all the citation counts which are used in this bibliometric analysis were retrieved from Scopus because it offers the more exhaustive citation data for virtually every article under consideration. While due to the different search approaches some documents were found uniquely in $W o S$, all those documents are also represented in Scopus which allowed retrieving the citation counts by directly searching for the title of the publications. The citation counts as well as the numbers of publications were retrieved on 24th of November 2016, when the searches as described in this chapter were performed.

The searches in both databases were limited to the peer-reviewed document types article and review which are the primary sources for new research results (Thomson Reuters 2008). Due to their blind review process, they guarantee the most useful and reliable source for literature reviews (Saunders et al. 2012; apud Garza-Reyes 2015). Initially, documents of any year before 2016 were permitted in order to see the evolution of publications over time, beginning with the first document published on the topic. As shown in Fig. 1 in the introduction, a constant growth in publications starts only after 2002 and therefore the results were limited to documents which were published in the period from 2002 through 2015 for any further analyses.

The goal of defining the search parameters was on one hand to find as many documents as possible which talk about Lean Philosophy in a healthcare environment while on the other hand to keep the amount of those documents low which focus on other topics. 
The search results pointed out variations for the term Lean, such as Lean Production, Lean Management, Lean Thinking, Toyota Production System, Lean/Toyota Production System, Toyota's Lean Manufacturing Principles, Toyota (Lean) Methods, Lean Principles, Lean Method, Lean Manufacturing, Lean Techniques, Lean Methodology and Lean Philosophy among others. To identify, which articles are exclusively related to the application of Lean in a healthcare environment, the titles and abstracts of all the articles were analyzed. Those which were not in the scope of this research were eliminated after double-checking the text of the article itself. In this process, we analyzed the synonyms of Lean Philosophy which are used in the literature and included those articles in our research which are dealing with Lean or its synonyms in healthcare. By doing so, we did not exclude synonyms of Lean without carefully reading and judging each article's title, abstract and content. However, local or national programs which were developed on the basis of Lean but use other denominations than Lean were not included in this bibliometric analysis. We configured our search criteria in a way that does not include studies in which Lean Philosophy is denominated in a different way. This decision was made to maintain the essence of Lean Philosophy and to not compromise the results of this research.

The search in Scopus found all articles which include both the word lean in the title and either one of the spellings healthcare or "health care" in title, abstract and/or keywords but do not include the terms "lean body weight", "body mass index" or "lean mass" in either title, abstract or keywords. It was complemented by checking for articles which use the word lean in the keywords and at least one of the expressions health care, healthcare, hospital, nurs*, "emergency department", "health system", medical, "quality of care", "primary care", rehabilitation, "health practice”, "emergency unit", "health services", surgical, surgeon, surgery, doctor, physician, "clinical laboratory" and "medical laboratory" in title, abstract and/or keywords and neither one of the terms "lean body weight", "body mass index" or "lean mass" in either title, abstract or keywords. The asterisk * replaces one or multiple characters in a word which makes it possible to search for words with the same beginning but different endings and quotation marks before and after multiple words mean that only words in exactly the stated order are searched for (Elsevier 2016).

As opposed to the database Scopus, it is not possible in WoS to search explicitly in the keywords which made it impossible to use the same search parameters. Therefore, a search for articles with include both the word lean and either one of the spellings "health care" or healthcare but none of the terms "lean body weight", "body mass index" and "lean mass" in the "Topic", which is the equivalent for Scopus' search in title, abstract and keywords.

All in all, the search in Scopus led to 734 results and the one in WoS, which was performed in the Web of Science ${ }^{\mathrm{TM}}$ Core Collection, resulted in 519 documents.

Waring and Bishop (2010) describe that when Lean Philosophy is applied in healthcare, it is often intertwined with other reforms and developments. Therefore, in order to avoid interferences, the focus of this bibliometric analysis lies in analyzing only those articles which are exclusively related to Lean Philosophy in a healthcare environment. This means that all documents which, to a significant extent, talk about Lean in other areas, talk about other principles than Lean or use the term lean in a different context had to be excluded. Additionally, non-accessible documents had to be excluded if the title and/or abstract did not contain sufficient information to make a decision.

Table 1 gives a comparative overview over the search results in Scopus and WoS as performed on 24th of November 2016. The percentage of excluded documents is noticeably higher in $W o S$ which can be attributed to the fact that the search engine of WoS made it necessary to also search for lean in the abstract and not only in keywords and title as in Scopus. 
Table 1 Results of the searches on Lean Healthcare in Scopus and WoS as performed on 24th of November 2016

\begin{tabular}{llr}
\hline Database & Scopus & Web of Science (WoS) \\
\hline Initial number of documents & 734 & 519 \\
Number of refined documents & 269 & 99 \\
Number of duplicates & & 60 \\
Final number of documents (all years before 2016) & & 308 \\
Final number of documents (in the period 2002-2015) & & 304 \\
\hline
\end{tabular}

The table shows that after the refinement 269 documents remained for the Scopus search and 99 for the one in WoS. With 60 publications showing up both in Scopus and in WoS, the total number of articles which are subject to this bibliometric analysis is 308 . As four of those documents were released before 2002, 304 documents remain for the analysis of the period from 2002 through 2015.

\section{Bibliometric analysis}

This section describes the analysis of the results which were obtained by the search as described in the previous section. As already mentioned only publications from 2002 through 2015 are analyzed.

Figure 2 shows the publications per year for this period. While the annual publications remain fairly low from 2002 through 2005, there is a leap from 2005 to 2006. In the year 2005, Jimmerson et al. (2005) and Spear (2005) published articles about the positive results of implementing Lean Healthcare, which greatly influenced the literature on the topic as they were directly cited in around $20 \%$ of the articles on Lean Healthcare from 2006 through 2015. Despite the high relevance of the article published by Spear (2005), it was not included in this bibliometric analysis due to the fact that it did not meet our search criteria as defined in "Research methodology" section. Over the period from 2006 through 2015, the figure depicts a relatively constant growth of publications and therefore a rise of the importance of the topic itself. This constant growth is highlighted by a trend line which

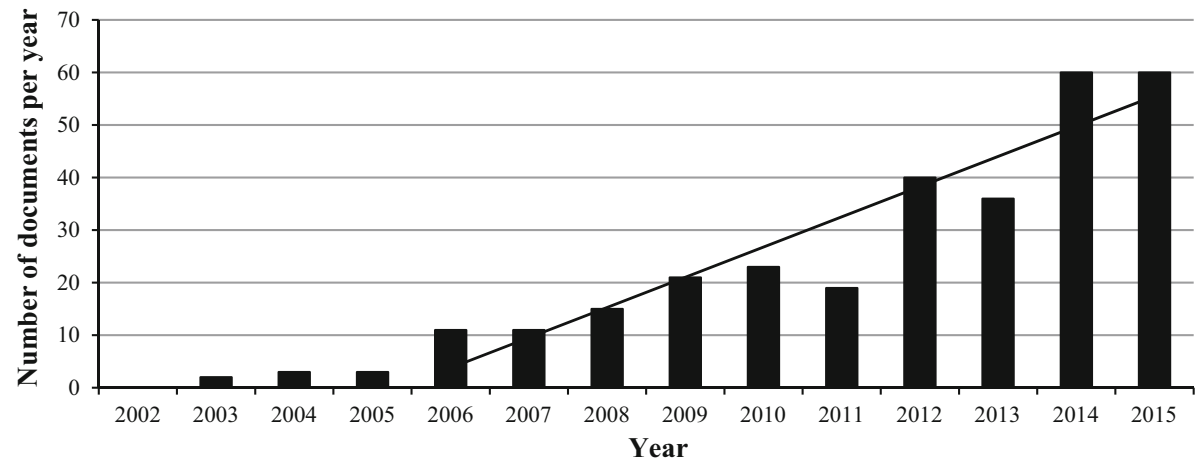

Fig. 2 Annual publications on Lean Healthcare from 2002 through 2015 (Based on the Scopus and WoS data resulting from the search as described in "Research methodology" section) 
appears inside the bar diagram. Starting with 11 documents in the years 2006 and 2007, the number of publications rises up to 60 articles in the years 2014 and 2015. Despite some discrepancies, the trend line suggests an even further increase in publications for the years to come, going along with a potentially raising significance of Lean Philosophy in the area of healthcare.

In the following subsections, the most cited countries, institutions, journals, authors and publications in literature on Lean Healthcare are analyzed.

\section{Country analysis}

Table 2 shows the six most cited countries in literature on Lean Healthcare, namely the United States with 1561 citations, the United Kingdom with 742 citations, Sweden with 409 citations, Australia with 321 citations, Canada and the Netherlands with 136 citations each.

The Virginia Mason Medical Center in Seattle (United States), the Royal Bolton NHS Foundation Trust in Farnworth (United Kingdom) and the Flinders Medical Centre in Adelaide (Australia) are three prime examples for the implementation of Lean Philosophy in healthcare (Radnor et al. 2012). This may be one reason why these three countries are among the four most cited countries.

The six most cited countries are also the six countries with the highest number of publications, however in a different order for the ranks three through five. The country with the highest amount of publications is the United States with 143 documents, having a great lead over the second ranked United Kingdom with 45 publications. These are still around twice as many publications as compared to Canada which is on the third rank with 23 documents, closely followed by Sweden with 17 and Australia with 14 publications. With nine published articles, the Netherlands takes the sixth rank.

Together these six countries are involved in 203 of the 304 articles which means that they make up for about two-thirds of the total publications. In the amount of 203 documents, those in which more than one of these countries is involved are only counted once.

To get a feeling for the weight of these countries with respect to the number of publications in this search as compared to the countries' publications in general, the data of the search was compared to the SJR Country Rankings (Scimago Lab 2016a). While the United States and the United Kingdom are among the top three countries regarding overall publications (the United States on the first place and the United Kingdom on the third one), their impact in this analysis is still considerably higher than in general, as the Unites States are involved in $47 \%$ of the publications in this search as opposed to $23 \%$ in general and the United Kingdom in $15 \%$ instead of $7 \%$. Canada, Australia, the Netherlands and Sweden achieve higher ranks in this search as opposed to their position in the overall rankings, with

Table 2 Analysis of most cited countries in literature on Lean Healthcare (Based on the Scopus and WoS data resulting from the search as described in "Research methodology" section)

\begin{tabular}{llcc}
\hline$\#$ & Country & Number of publications & Citation count \\
\hline 1 & United States & 143 & 1561 \\
2 & United Kingdom & 45 & 742 \\
3 & Sweden & 17 & 409 \\
4 & Australia & 14 & 321 \\
5 & Canada & 23 & 136 \\
& Netherlands & 9 & 136 \\
\hline
\end{tabular}


Canada being number three instead of number seven, Australia achieving rank five instead of 11 and the Netherlands rank six instead of 14. Sweden even achieves the fourth position instead of the 18th which underlines the relevance of this topic in Swedish research.

As mentioned in the introduction, Costa and Godinho Filho (2016) and D' Andreamatteo et al. (2015) analyze the number of publications by country in their literature reviews as well. They also come to the result that the United States is the country which publishes by far the most articles on the topic, followed by the United Kingdom which still has a clear lead over the other countries. The fact that Australia is the only other country that D'Andreamatteo et al. (2015) explicitly state and that the Netherlands, Sweden and Canada take the ranks three through five in the review by Costa and Godinho Filho (2016) further validate the results of this subsection's country analysis.

\section{Institution analysis}

Table 3 gives an overview of the six most cited institutions in literature on Lean Healthcare. The first rank goes to the Swedish Linköpings Universitet. The second place is not taken by a university but by an Australian medical center. This "public teaching hospital and medical school, co-located with Flinders University and Flinders Private Hospital" (SA Health 2009) is one of the three prime examples of implementing Lean Healthcare that were mentioned in the previous subsection. The third, the fourth and the sixth rank go to the University of Michigan, the University of Iowa and the University of Washington which are all located in the United States. The fifth most cited institution is the Lancaster University which represents the United Kingdom.

Therefore, the six institutions with the highest amount of citations in literature on Lean Healthcare are located in the four most cited countries as indicated in the previous subsection.

By reviewing the departments which were involved in the articles published by the top six institutions, it was noticed that the large part of them are purely medical departments like "Department of Internal Medicine" or "Department of Emergency Medicine". This deviates from the authors' expectation that the great majority would be business and management departments.

\section{Journal analysis}

In Table 4, the six most cited journals in literature on Lean Healthcare can be seen. Due to the fact that the 304 documents in this search were published in as many as 199 different

Table 3 Analysis of most cited institutions in literature on Lean Healthcare (Based on the Scopus and WoS data resulting from the search as described in "Research methodology" section)

\begin{tabular}{lllll}
\hline$\#$ & Institution & Country & Number of publications & Citation count \\
\hline 1 & Linköpings Universitet & Sweden & 6 & 263 \\
2 & Flinders Medical Centre & Australia & 4 & 236 \\
3 & University of Michigan & United States & 10 & 223 \\
4 & University of Iowa & United States & 5 & 205 \\
5 & Lancaster University & United Kingdom & 2 & 152 \\
6 & University of Washington & United States & 8 & 145 \\
\hline
\end{tabular}


Table 4 Analysis of most cited journals in literature on Lean Healthcare (Based on the Scopus and WoS data resulting from the search as described in "Research methodology" section)

\begin{tabular}{|c|c|c|c|c|c|c|}
\hline$\#$ & Journal & Field of research & $\begin{array}{l}\text { SJR } \\
(2014)\end{array}$ & ISSN & $\begin{array}{l}\text { Number of } \\
\text { publications }\end{array}$ & $\begin{array}{l}\text { Citation } \\
\text { count }\end{array}$ \\
\hline 1 & $\begin{array}{l}\text { Leadership in Health } \\
\text { Services }\end{array}$ & Medicine: Health Policy & 0.306 & $1366-0756$ & 8 & 240 \\
\hline 2 & BMJ Quality and Safety & $\begin{array}{l}\text { Medicine } \\
\text { Medicine: Health Policy }\end{array}$ & 2.591 & $2044-5423$ & 7 & 211 \\
\hline 3 & $\begin{array}{l}\text { Annals of Emergency } \\
\text { Medicine }\end{array}$ & $\begin{array}{l}\text { Medicine } \\
\text { Medicine: Emergency } \\
\text { Medicine }\end{array}$ & 1.942 & 0196-0644 & 4 & 182 \\
\hline 4 & $\begin{array}{l}\text { Social Science and } \\
\text { Medicine }\end{array}$ & $\begin{array}{l}\text { Social Sciences: Health } \\
\text { (social science) } \\
\text { Arts and Humanities: } \\
\text { History and Philosophy } \\
\text { of Science }\end{array}$ & 1.894 & 0277-9536 & 2 & 169 \\
\hline 5 & $\begin{array}{l}\text { Joint Commission } \\
\text { Journal on Quality and } \\
\text { Patient Safety }\end{array}$ & $\begin{array}{l}\text { Leadership and } \\
\text { Management } \\
\text { Medicine }\end{array}$ & 0.750 & $1553-7250$ & 5 & 123 \\
\hline 6 & $\begin{array}{l}\text { Journal of Hospital } \\
\text { Medicine (Online) }\end{array}$ & $\begin{array}{l}\text { Nursing: Fundamentals } \\
\text { and Skills } \\
\text { Nursing: Leadership and } \\
\text { Management } \\
\text { Nursing: Care Planning } \\
\text { Nursing: Assessment and } \\
\text { Diagnosis } \\
\text { Medicine: Health Policy }\end{array}$ & 0.759 & $1553-5606$ & 1 & 111 \\
\hline
\end{tabular}

journals, the numbers of citations remain fairly low, even in the top six. The numbers of the journal BMJ Quality and Safety include the articles of the journal Quality and Safety in Health Care as the journal was formerly known according to Scopus. In all of the six most cited journals, the high ranking is mainly or completely due to the citations of two documents. Two publications of the journal Leadership in Health Services are cited 212 times out of the journal's total citation count of 240, in the journal BMJ Quality and Safety two articles are responsible for 188 of the 211 citations, in the Annals of Emergency Medicine two publications make up for 175 of the 182 citations, in the journal Social Science and Medicine two documents are responsible for all 169 citations, in the Joint Commission Journal on Quality and Patient Safety 109 of the journal's 123 citations are due to two articles and in the Journal of Hospital Medicine (Online) all 111 citations stem from one publication. Seven of these articles are among the 10 most cited publications which will be further elaborated in Publication analysis " section.

While five of these journals (Leadership in Health Services, BMJ Quality and Safety, Social Science and Medicine, Joint Commission Journal on Quality and Patient Safety and Journal of Hospital Medicine (Online)) are related to health policy and management aspects, the last one (Annals of Emergency Medicine) is a purely medical journal. This is, in accordance with the observation of the previous subsection, against the authors' assumption that all of the most cited journals would focus on management topics. While analyzing the journals, it is important to consider the ranking within the context of the subject areas as the publication and citation count may differ by discipline (Thomson Reuters 2014). Comparing the subject areas Medicine and Medicine: Health Policy, it can 
Table 5 Analysis of most cited authors in literature on Lean Healthcare (Based on the Scopus and WoS data resulting from the search as described in "Research methodology" section)

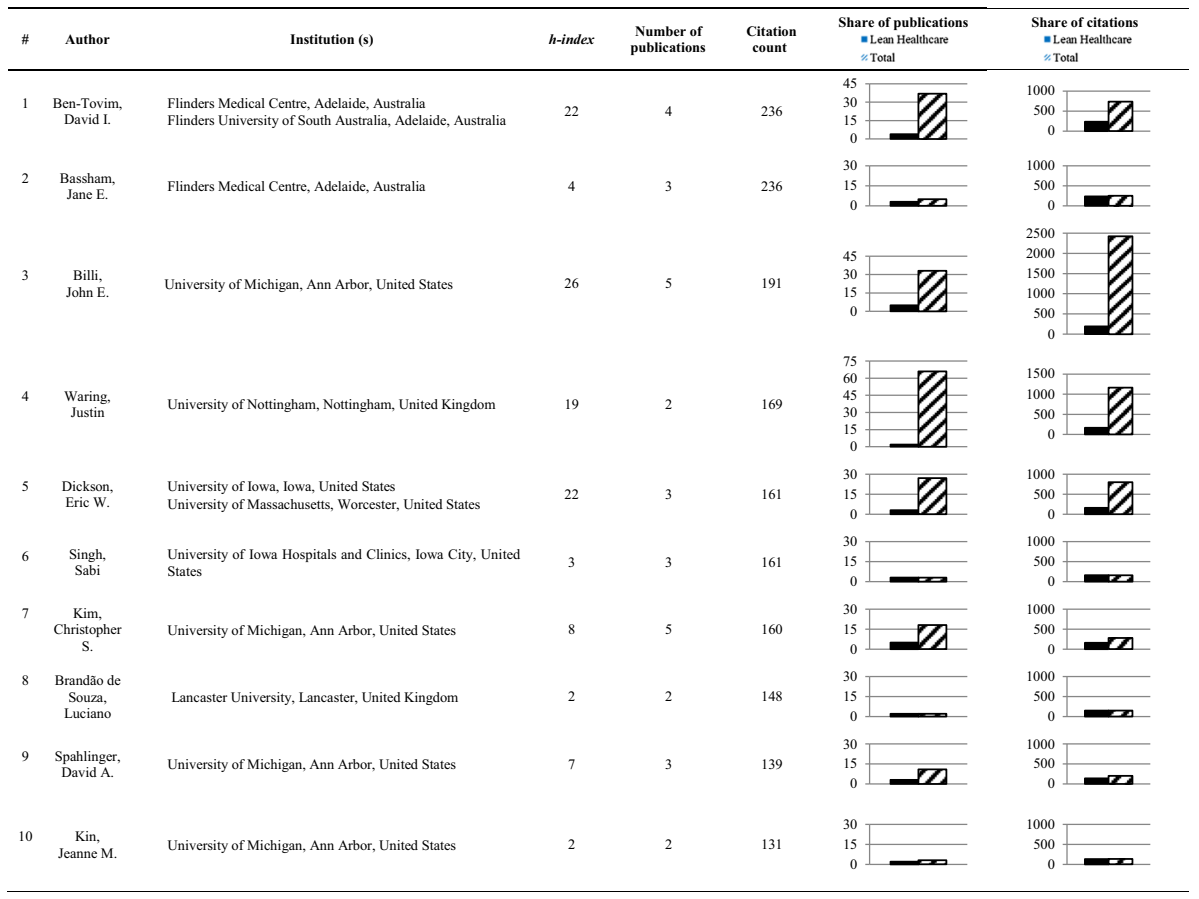

be seen that in general journals in the former area have a higher citation count. Over the last 3 years, each journal in the subject area Medicine averagely publishes more than oneand-a-half as many articles as journals in the subject area Medicine: Health Policy and each of these documents is cited around one-and-a-half as many times on average (Scimago Lab 2016b).

For further information about the six journals, Table 4 also states each journal's field of research and SJR as indicated by Scopus. The SJR, or SCImago Journal Rank, "is a measure of [a] journal's impact, influence or prestige. It expresses the average number of weighted citations received in the selected year by the documents published in the journal in the three previous years" (Scimago Lab 2016b).

\section{Author analysis}

The 10 most cited authors in literature on Lean Healthcare are shown in Table 5 along with their respective institutions. Except for J. Waring, all authors represent four of the six most cited institutions as described in "Institution analysis" section and can be grouped along them. The institutions which make up these groups as well as those which are listed in the table were specified by using the author information as indicated in Scopus and in the relevant articles themselves.

The first group is represented by the two most cited authors D.I. Ben-Tovim and J.E. Bassham of the Flinders Medical Centre who cooperated in three publications. They are both co-authors in one article by D.L. King of the same institution and the remaining two 
articles are authored by D.I. Ben-Tovim himself and co-authored by J.E. Bassham. Furthermore D.I. Ben-Tovim acted as co-author in an article by B. Crane who also works at the Flinders Medical Centre. Because the article by B.Crane was not cited until the year 2015, D.I. Ben-Tovim and J.E. Bassham share the first rank with 236 citations each. The second group consists of authors related to the University of Michigan and includes the third most cited author J.E. Billi. Although not being the first author of any document in this search, he co-authored five articles. One of them is by R.M. Collar of the same university, while four of them are by C.S. Kim who is the seventh most cited author and also works at the University of Michigan. In addition to these four articles, C.S. Kim co-authored a publication of T. Platchek of the Stanford University. In three of the four publications by C.S. Kim, the ninth most cited author D.A. Spahlinger worked as a co-author and J.M. Kin on rank 10 participated in two of the articles co-authored by D.A. Spahlinger. Both D.A. Spahlinger and J.M. Kin work at the University of Michigan as well. The third group consists of E.W. Dickson of the University of Iowa and S. Singh of University of Iowa Hospitals and Clinics. They share the fifth rank for participating in the same three publications, E.W. Dickson as lead author and S. Singh as co-author. The last group consists of only one author who published two articles on the topic, namely L. Brandão de Souza who works at the Lancaster University and takes the eighth rank. Besides these four groups, $J$. Waring who is the fourth most cited author acted as first author of one document and coauthored one article by Z.J. Radnor.

One publication of each the first, the second and the fourth group as well as the article by Z.J. Radnor which was co-authored by J. Waring is among the 10 most cited publications which will be analyzed in the subsequent subsection. Although not being among the 10 most cited publications, two articles by E.W. Dickson and S.Singh of the third group are the 12th and 13th most cited documents. Of all authors who took part in publications about Lean Healthcare as defined in this article, only the authors J. Thor, J.E. Billi and C.S. Kim contributed to more than four articles.

Table 5 also shows how many articles the authors published on Lean Healthcare in comparison to the total amount of their publications in the period from 2002 through 2015 and furthermore compares the accumulated citations of the relevant documents. Depending on the author this varies widely: While all of J.M. Kin's citations in this period as well as all of S. Singh's and L. Brandão de Souza's publications and therefore all their corresponding citations are about Lean Healthcare, for other authors the publications about Lean Healthcare only account for a very small percentage of their total output. In terms of publication quantity, the percentage of publications about Lean Healthcare of $J$. Waring is the lowest among these 10 authors with $3 \%$ and in terms of citations, J.E. Billi has the lowest rate with $8 \%$. The share of publications about Lean Healthcare in the total scientific output appears to be negatively correlated to the $h$-index which was developed by J.E. Hirsch and states the number of publications of an author which have more citations than this number (Elsevier 2016). As the $h$-index generally increases with both the quantity of publications and the frequency in which these publications are cited, it stands to reason that the importance of a single specific topic decreases with an increasing $h$-index in comparison to the total output. While there is no perfect negative correlation, the six authors with h-indices below 10 are the six authors who have the highest percentage of publications about Lean Healthcare as compared to their total output, both in number of publications and in citations. Correspondingly, the four authors with h-indices above 10 are the four authors with the lowest percentages.

The articles about Lean Healthcare make up for a bigger percentage of the total publications in terms of citations than in terms of publishing quantity. This is due to the fact that 
Table 6 Analysis of most cited publications in literature on Lean Healthcare, published between 2002 and 2015 (Based on the Scopus and WoS data resulting from the search as described in "Research methodology" section)

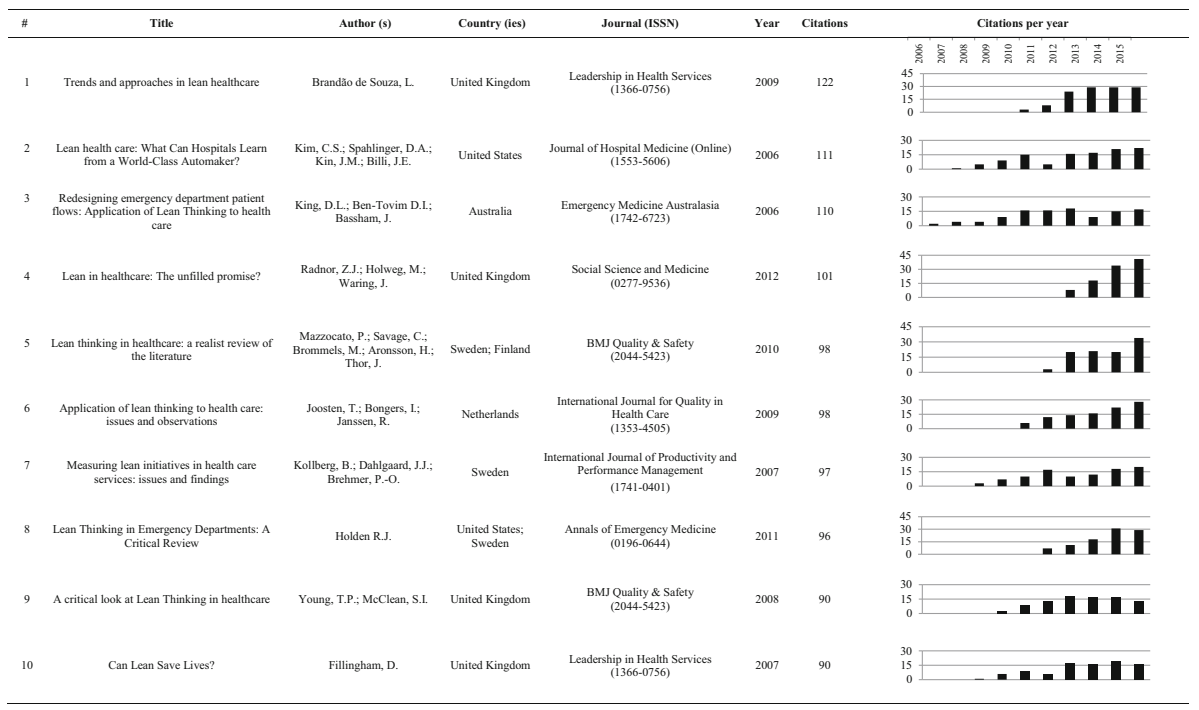

for all authors except J.E. Billi at least one publication about Lean Healthcare is among his/ her four most cited documents in the period from 2002 through 2015. The second, third and fourth most cited document of D.I. Ben-Tovim, the three most cited publications of J.E. Bassham, the second most cited document of J. Waring, the second and third most cited publication of E.W. Dickson, as well as the three most cited articles of S. Singh are about Lean Healthcare. The list continues with the most and fourth most cited publication of C.S. Kim and the two most cited articles of L. Brandão de Souza, as well as the first and third most cited article of D.A. Spahlinger and the two most cited publications of J.M. Kin.

\section{Publication analysis}

Table 6 shows the 10 publications with the highest amount of citations, which accumulate for 1013 of the 3240 citations of all the articles in this search. This means that around 3\% of the documents are responsible for over $30 \%$ of the total citations. As the ranks five and six as well as the ranks nine and 10 have the same amount of citations, they were ordered by their publication year, with the newest publication achieving the higher rank because it was cited just as often in less time.

Eight of the 10 most cited documents (Brandão de Souza 2009; Fillingham 2007; Holden 2011; Joosten et al. 2009; Kim et al. 2006; King et al. 2006; Mazzocato et al. 2010; Young and McClean 2008) are about the practical application and implementation of Lean Philosophy in a healthcare environment which demonstrates the practical nature of the literature on Lean Healthcare. This conclusion was emphasized by finding 88 documents which include the terms application, implementation and case study in different spellings in the document titles. Thus, almost 30\% of the 304 publications already talk about practical aspects in the title. Two other reoccurring topics in the 10 most cited publications are theoretic overviews and literature reviews. 
As described in the previous subsection, eight of the 10 most cited authors are represented in one publication each. Furthermore, the 10 most cited publications exclusively origin from the five countries with the highest citation counts except for a co-authorship from Finland in the article on rank six. Moreover, seven of the 10 most cited publications where published in the six most cited journals.

Table 6 also shows how the total amount of citations is distributed over the years. Overall, the amount of citations is rising over the years, but there exist various deviations. The publications on the fourth and sixth rank are the only ones whose citations actually rise in each consecutive year, while the citations of the article on the first place never decreased, but remained stable from 2013 through 2015. While not without irregularities, the publications on rank two, three, five and seven are cited in an increasing fashion over the years as well. However, the growth of the publications on rank three and seven occur in two phases, respectively.

One thing, the other three documents (namely the ranks eight through 10) have in common, is that all of them mark a decrease in publications in 2015. The document on the eighth rank was increasingly cited until 2014 and only registers a decrease in 2015 which makes it difficult to determine a trend as this could either mean an irregularity or the beginning of a decline in citations. The article on place nine was increasingly cited until 2012 and shows a downward trend thereafter. The publication on the 10th rank is alternately growing and decreasing over the years, but the citations grow constantly if the citations of two consecutive years are considered together consistently.

The article on rank four by Radnor et al. (2012) is the publication which achieved the most citations per year-both the highest value achieved in one specific year and the highest value in average over the years after it has been published.

\section{Future research tendencies}

To evaluate future research tendencies, the articles which were published in 2015 were analyzed with respect to the scientific literature gaps which they propose. It was chosen to limit this analysis to articles from 2015 because the proposals for future research are probably not resolved by now. Of the 60 articles on Lean Healthcare which were published in 2015, 24 were not accessible and 17 did not include proposals for further research. Therefore, only the 19 remaining articles which are mapped in Fig. 3 were analyzed.

As can be seen in Fig. 3, we divided the scientific literature gaps of these 19 articles (illustrated as round boxes) in 12 topics (illustrated as small grey rectangular boxes) along similarity in their proposals. Thereafter, we further summarized these topics in the following four main tendencies (illustrated as big white rectangular boxes):

(1) Evaluate the implementation of Lean Philosophy in a healthcare environment by developing indices, frameworks and additional studies.

(2) Amplify basic knowledge by consistently defining what Lean Healthcare is, how the integration of Lean Philosophy into healthcare works and which Lean Tools fit the healthcare context.

(3) Investigate challenges and success stories, that is to say instead of only stating or confirming success, negative outcomes need to be included in the literature to avoid making the same mistakes again and positive results need to be examined causally to make them reproducible. 


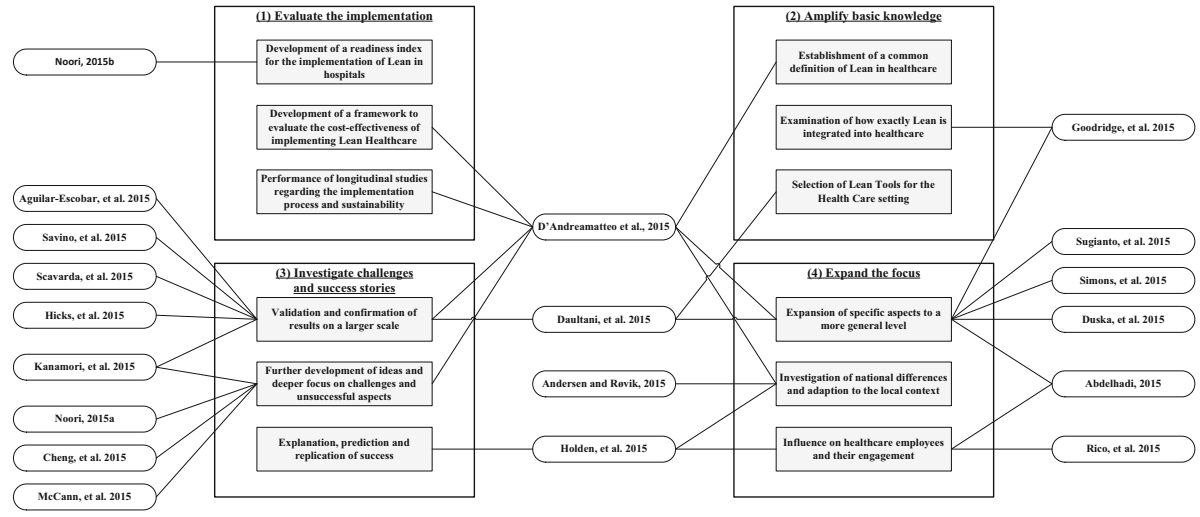

Fig. 3 Map of future research directions and the corresponding articles which suggest them

(4) Expand the focus by transferring results which were achieved in particular settings to be universally applicable and investigating the interrelation between staff and Lean Implementation.

The first tendency includes the development of a readiness index for Lean Implementation in hospitals as proposed by Noori (2015b), and D'Andreamatteo et al. (2015) suggest the development of a framework to evaluate the cost-effectiveness of implementing Lean Healthcare as well as the performance of longitudinal studies regarding the implementation process and sustainability.

The second tendency deals with the lack of a common definition of Lean in healthcare (D'Andreamatteo et al. 2015), the examination of the manner in which Lean Philosophy is integrated into healthcare (Goodridge et al. 2015) and the selection of appropriate Lean Tools for the particular healthcare setting (Daultani et al. 2015).

The third tendency stems from documents about the proposal of new models and about the implementation of Lean Philosophy, as they express the need for validation and confirmation of their results on a larger scale (Aguilar-Escobar et al. 2015; Daultani et al. 2015; D’Andreamatteo et al. 2015; Hicks et al. 2015; Kanamori et al. 2015; Savino et al. 2015; Scavarda et al. 2015). Some authors call for further development of ideas they proposed and for a deeper focus on challenges and unsuccessful aspects they encountered (Cheng et al. 2015; D'Andreamatteo et al. 2015; Kanamori et al. 2015; McCann et al. 2015; Noori 2015a). Holden et al. (2015) ask for the explanation, prediction and replication of success instead of only conforming it.

As many publications focus on very specific aspects, the fourth tendency is based around expanding these aspects to a more general level with respect to different processes, tools and target audiences, to only name a few (Abdelhadi 2015; Daultani et al. 2015; D'Andreamatteo et al. 2015; Duska et al. 2015; Goodridge et al. 2015; Simons et al. 2015; Sugianto et al. 2015). D'Andreamatteo et al. (2015) and Holden et al. (2015) demand the investigation of national differences, while Andersen and Røvik (2015) ask for adaption of Lean Philosophy to the local context. A related topic is the investigation of Lean Healthcare's influence on healthcare employees and their engagement in Lean Implementations (Abdelhadi 2015; Holden et al. 2015; Rico et al. 2015). 


\section{Conclusion}

The study of Lean Philosophy in a healthcare environment is a topic of rising importance, both in literature as the strongly growing publications indicate and in practice as a good deal of these publications are about applying or implementing Lean Philosophy in healthcare. This article dealt with the absence of an up-to-date bibliometric analysis on articles which are exclusively related to Lean Philosophy in a healthcare environment in order to offer guidance on how the existing literature is structured as well as to present directions of research which are so far not sufficiently covered by the literature.

The article investigated the evolution of publications on Lean Healthcare and identified a significant growth over the last 10 years. By comparing the most cited countries, it was found that the United States, the United Kingdom and Australia are of major importance, not least because three prime examples for the successful application of Lean Healthcare were performed there. Sweden also has an essential role as the most cited institution, namely the Linköpings Universitet, is located there. With respect to authors and institutions, four research groups at the Flinders Medical Centre (D.I. Ben-Tovim, J. Bassham, D.L. King and B. Crane), the University of Michigan (J.E. Billi, C.S. Kim, D.A. Spahlinger and R.M. Collar), the University of Iowa (E.W. Dickson and S. Singh) and the Lancaster University (L. Brandão de Souza) are of significant influence in this field. The most cited journals in literature on Lean Healthcare are either related to health policy and management aspects (Leadership in Health Services, BMJ Quality and Safety, Social Science and Medicine, Joint Commission Journal on Quality and Patient Safety and Journal of Hospital Medicine (Online)) or have a purely medical focus (Annals of Emergency Medicine). By analyzing the most cited articles, the importance of practical aspects in literature about Lean Healthcare was confirmed. Finally, four main tendencies for future research on Lean Healthcare were identified: to expand the focus, to investigate challenges and success stories, to amplify basic knowledge and to evaluate the implementation.

By structuring data of publications on Lean Healthcare bibliometrically, this article's main scientific contribution lies in the systematization of literature on Lean Healthcare, the specification of publications, authors, journals, institutions and countries with high relevance for this field as well as the identification and summarization of scientific gaps which were proposed in recent articles. By doing so, this bibliometric analysis encourages the review and consolidation of already existing directions in this field of research and the exploration of new ones.

In terms of its applied contribution, this article helps hospitals and professionals which want to apply Lean Healthcare to find their way along this field of research and to easily access the most important literature. As the application of Lean Philosophy in a healthcare environment is still a relatively new approach, they might face uncertainties and challenges before or during its implementation. This article identifies and structures the major publications and research groups in the field and thereby allows to adapt suitable findings for the practical implementation of Lean Philosophy in hospitals and other healthcare institutions to improve the patient experience.

One limitation of this article is the omission of an analysis of the most frequently used keywords because the relevant data as supplied by the databases was insufficient and led to insignificant results. Beyond that, there are restrictions regarding the scope of the bibliometric analysis per se. Obviously, only articles which conform to the search parameters and the refinement criteria as defined in "Research methodology" section were included and a different definition would lead to other results. This is a limitation of this study that 
restricts research results and does not allow for a complete understanding of Lean Philosophy in a healthcare environment. Another limitation is that the results are restricted to the databases Scopus and $W o S$ and almost exclusively contain articles which are written in the English language.

Further research should investigate differences and similarities of Lean Healthcare from a medical and a business perspective and future bibliometric analyses could focus on the implementation of Lean Healthcare in emergency departments as this area of application reoccurred throughout this analysis.

\section{References}

Abdelhadi, A. (2015). Investigating emergency room service quality using lean manufacturing. International Journal of Health Care Quality Assurance, 28(5), 510-519.

Aguilar-Escobar, V. G., Bourque, S., \& Godinho-Gallego, N. (2015). Hospital kanban system implementation: Evaluating satisfaction of nursing personnel. Investigaciones Europeas de Direccion $y$ Economia de la Empresa, 21(3), 101-110.

Andersen, H., \& Røvik, K. A. (2015). Lost in translation: A case-study of the travel of lean thinking in a hospital. BMC Health Services Research, 15(1), article number 1081.

Ball, R., \& Tunger, D. (2006). Bibliometric analysis-A new business area for information professionals in libraries? Scientometrics, 66(3), 561-577.

Brandão de Souza, L. (2009). Trends and approaches in lean healthcare. Leadership in Health Services, 22(2), 121-139.

Cheng, S. Y., Bamford, D., Papalexi, M., \& Dehe, B. (2015). Improving access to health services-challenges in Lean application. International Journal of Public Sector Management, 28(2), 121-135.

Costa, L. B. M., \& Godinho Filho, M. (2016). Lean healthcare: Review, classification and analysis of literature. Production Planning and Control, 27(10), 823-836.

D’Andreamatteo, A., Ianni, L., Lega, F., \& Sargiacomo, M. (2015). Lean in healthcare: A comprehensive review. Health Policy, 119(9), 1197-1209.

Daultani, Y., Chaudhuri, A., \& Kumar, S. (2015). A decade of lean in healthcare: Current state and future directions. Global Business Review, 16(6), 1082-1099.

Dickson, E. W., Singh, S., Cheung, D. S., Wyatt, C. C., \& Nugent, A. S. (2009). Application of lean manufacturing techniques in the emergency department. The Journal of Emergency Medicine, 37(2), $177-182$.

Diem, A., \& Wolter, S. C. (2013). The use of bibliometrics to measure research performance in education sciences. Research in Higher Education, 54(1), 86-114.

Duska, L. R., Mueller, J., Lothamer, H., Pelkofski, E. B., \& Novicoff, W. M. (2015). Lean methodology improves efficiency in outpatient academic gynecologic oncology clinics. Gynecologic Oncology, $138(3), 707-711$.

Elsevier. (2016). Scopus help. http://help.elsevier.com/app/answers/list/p/8150. Accessed May 17, 2016.

Fillingham, D. (2007). Can lean save lives? Leadership in Health Services, 20(4), 231-241.

Garousi, V. (2015). A bibliometric analysis of the Turkish software engineering research community. Scientometrics, 105(1), 23-49.

Garza-Reyes, J. A. (2015). Lean and green-a systematic review of the state of the art literature. Journal of Cleaner Production, 102, 18-29.

Gonçalves, B., \& Perra, N. (2015). Introduction. In B. Gonçalves \& N. Perra (Eds.), Social Phenomena: From data analysis to models (pp. 1-12). Cham: Springer.

Gonzalez, R., \& Martins, M. F. (2015). Competências habilitadoras da melhoria contínua: estudo de casos em empresas do setor automobilístico e de bens de capital. Gestão \& Produção, 22(4), 725-742.

Goodridge, D., Westhorp, G., Rotter, T., Dobson, R., \& Bath, B. (2015). Lean and leadership practices: development of an initial realist program theory. BMC Health Services Research, 15(1), article number 362.

Health, S. A. (2009). Flinders medical centre. http://www.flinders.sa.gov.au/. Accessed May 18, 2016.

Hicks, C., McGovern, T., Prior, G., \& Smith, I. (2015). Applying lean principles to the design of healthcare facilities. International Journal of Production Economics, 170, 677-696.

Holden, R. J. (2011). Lean thinking in emergency departments: A critical review. Annals of Emergency Medicine, 57(3), 265-278. 
Holden, R. J., Eriksson, A., Andreasson, J., Williamsson, A., \& Dellve, L. (2015). Healthcare workers' perceptions of lean: A context-sensitive, mixed methods study in three Swedish hospitals. Laboratory Medicine, 46(3), 259-264.

Iritani, D. R., Morioka, S. N., Carvalho, M. M. D., \& Ometto, A. R. (2015). Análise sobre os conceitos e práticas de Gestão por processos: Revisão sistemática e bibliometria. Gestão \& Produção, 22(1), 164-180.

Jimmerson, C., Weber, D., \& Sobek, D. K., II. (2005). Reducing waste and errors: Piloting lean principles at intermountain healthcare. Joint Commission Journal on Quality and Patient Safety, 31(5), 249-257.

Joosten, T., Bongers, I., \& Janssen, R. (2009). Application of lean thinking to health care: issues and observations. International Journal for Quality in Health Care, 21(5), 341-347.

Kanamori, S., Sow, S., Castro, M.C., Matsuno, R., Tsuru, A., \& Jimba, M. (2015). Implementation of 5S management method for lean healthcare at a health center in Senegal: A qualitative study of staff perception. Global Health Action, 8(1), article number 27256.

Kästli Meier, B. (1994). Lean-Production: Umstrittene Arbeitsorganisation auch im Gesundheitswesen. Die Rückseite der Medaille: Arbeitslosigkeit. Krankenpflege Soins Infirmiers, 87(6), 1-5.

Kim, C. S., Spahlinger, D. A., Kin, J. M., \& Billi, J. E. (2006). Lean health care: What can hospitals learn from a world-class automaker? Journal of Hospital Medicine (Online), 1(3), 191-199.

King, D. L., Ben-Tovim, D. I., \& Bassham, J. (2006). Redesigning emergency department patient flows: Application of Lean thinking to health care. Emergency Medicine Australasia, 18(4), 391-397.

Kollberg, B., Dahlgaard, J. J., \& Brehmer, P.-O. (2007). Measuring lean initiatives in health care services: issues and findings. International Journal of Productivity and Performance Management, 56(1), 7-24.

Liker, J. K. (2004). The toyota way. Madison: McGraw-Hill.

Mazzocato, P., Savage, C., Brommels, M., Aronsson, H., \& Thor, J. (2010). Lean thinking in healthcare: a realist review of the literature. BMJ Quality \& Safety, 19(5), 376-382.

McCann, L., Hassard, J. S., Granter, E., \& Hyde, P. J. (2015). Casting the lean spell: The promotion, dilution and erosion of lean management in the NHS. Human Relations, 68(10), 1557-1577.

Merriam-Webster. (2015). Health care. http://www.merriam-webster.com/dictionary/health\%20care. Accessed June 21, 2016.

Mongeon, P., \& Paul-Hus, A. (2016). The journal coverage of web of science and scopus: A comparative analysis. Scientometrics, $106(1), 213-228$.

Moraros, J., Lemstra, M., \& Nwankwo, C. (2016). Lean interventions in healthcare: do they actually work? A systematic literature review. International Journal for Quality in Health Care, 28(2), 150-165.

Noori, B. (2015a). Identifying critical issues in lean implementation in hospitals. Hospital Topics, 93(2), 44-52.

Noori, B. (2015b). The critical success factors for successful lean implementation in hospitals. International Journal of Productivity and Quality Management, 15(1), 108-126.

OECD. (2002). Frascati manual (6th ed.). Paris: OECD.

Papadopoulos, T., Radnor, Z., \& Merali, Y. (2011). The role of actor associations in understanding the implementation of Lean thinking in healthcare. International Journal of Operations \& Production Management, 31(2), 167-191.

Pfaff, H. (1994). Lean Production - ein Modell für das Krankenhaus? Gefahren, Chancen. Denkanstöße. Zeitschrift für Gesundheitswissenschaften, 2(1), 61-80.

Printezis, A., \& Gopalakrishnan, M. (2007). Current pulse: Can a production system reduce medical errors in health care? Quality Management in Health care, 16(3), 226-238.

Radnor, Z. J., Holweg, M., \& Waring, J. (2012). Lean in healthcare: The unfilled promise? Social Science and Medicine, 74(3), 364-371.

Rico, F., Yalcin, A., \& Eikman, E. A. (2015). Technology integration performance assessment Using Lean principles in health care. American Journal of Medical Quality, 30(4), 374-381.

Saunders, M., Lewis, P., \& Thornhill, A. (2012). Research methods for business students (6th ed.). Essex: Pearson Education Ltd.

Savino, M. M., Mazza, A., \& Marchetti, B. (2015). Lean manufacturing within critical healthcare supply chain: An exploratory study through value chain simulation. International Journal of Procurement Management, 8(1-2), 3-24.

Scavarda, A. L., Machado, C. M. L., Vaccaro, G., \& Korzenowski, A. L. (2015). A management model for decision making at the hospital supply chain to minimize waste. Chemical Engineering Transactions, 45, 529-534.

Scimago Lab. (2016a). Country rankings. http://www.scimagojr.com/countryrank.php. Accessed May 18, 2016.

Scimago Lab. (2016b). Journal rankings. http://www.scimagojr.com/journalrank.php. Accessed November $27,2016$. 
Simons, P. A. M., Benders, J., Marneffe, W., Pijls-Johannesma, M., \& Vandijck, D. (2015). Workshops as a useful tool to better understand care professionals' views of a lean change program. International Journal of Health Care Quality Assurance, 28(1), 64-74.

Spear, S. (2005). Fixing health care from the inside. Today. Harvard Business Review, 83(9), 78-91.

Sugianto, J. Z., Stewart, B., Ambruzus, J. M., Arista, A., Park, J. Y., Cope-Yokoyama, S., et al. (2015). Applying the principles of lean production to gastrointestinal biopsy handling: From the Factory Floor to the Anatomic Pathology Laboratory. Lab Medicine, 46(3), 259-264.

Thomson Reuters. (2008). Whitepaper using bibliometrics: A guide to evaluating research performance with citation data. New York: Thomson Reuters.

Thomson Reuters. (2014). In cites indicators handbook. New York: Thomson Reuters.

United Nations. (2015). Transforming our world: The 2030 agenda for sustainable development. New York: United Nations.

Waring, J. J., \& Bishop, S. (2010). Lean healthcare: Rhetoric, ritual and resistance. Social Science and Medicine, 71(7), 1332-1340.

World Health Organization. (2016). Health topics - Primary health care. http://www.who.int/topics/ primary_health_care/en/. Accessed June 21, 2016.

Young, T. P., \& McClean, I. P. (2008). A critical look at Lean Thinking in healthcare. BMJ Quality \& Safety, 17(5), 382-386.

Zhang, J., \& Guan, J. (2017). Scientific relatedness and intellectual base: a citation analysis of un-cited and highly-cited papers in the solar energy field. Scientometrics, 110(1), 141-162. 